Research article

\title{
Abduction paresis with rostral pontine and/or mesencephalic lesions: Pseudoabducens palsy and its relation to the so-called posterior internuclear ophthalmoplegia of Lutz Frank Thömke* and Hanns Christian Hopf
}

\author{
Address: Deparment of Neurology, University of Mainz, Mainz, Germany \\ E-mail: Frank Thömke* - thoemke@neurologie.klinik.uni-mainz.de; Hanns Christian Hopf - hopf@neurologie.klinik.uni-mainz.de \\ *Corresponding author
}

This article is available from: http://www.biomedcentral.com//47/-2377///4

(C) 200I Thömke and Hopf; licensee BioMed Central Ltd. Verbatim copying and redistribution of this article are permitted in any medium for any noncommercial purpose, provided this notice is preserved along with the article's original URL. For commercial use, contact info@biomedcentral.com

\begin{abstract}
Background: The existence of a prenuclear abduction paresis is still debated.

Methods: In a retrospective design, we identified 22 patients with isolated unilateral $(n=20)$ or bilateral $(n=2)$ abduction paresis and electrophysiologic abnormalities indicating rostral pontine and/or mesencephalic lesions. Another II patients had unilateral abduction paresis with additional ocular motor abnormalities indicating midbrain dysfunction. Eight of these II patients also had electrophysiological abnormalities supporting this location. Electrophysiological examinations in all patients included masseter and blink reflexes (MassR, BlinkR), brainstem auditory evoked potentials (BAEP), and direct current elctro-oculography (EOG).

Results: Unilateral MassR abnormalities in patients with unilateral abduction paresis were seen in 17 patients and were almost always (in 16 of 17 patients) on the side of the abduction paresis. Another I I patients had bilateral MassR abnormalities. BlinkR was always normal. EOG disclosed slowed abduction saccades in the non-paretic eye in 6 patients and slowed saccades to the side opposite to the abduction paresis in another 5 patients. Re-examinations were done in 27 patients showing normalization or improvement of masseter reflex abnormalities in 18 of 20 patients and in all patients with EOG abnormalities. This was always associated with clinical improvement.

Conclusions: Electrophysiologically documented or clinically evident rostral pontine and/or mesencephalic lesions in our patients exclude an infranuclear intrapontine 6th nerve lesion and indicate the existence of an abduction paresis of prenuclear origin. An increased tone of the antagonistic medial rectus muscle during lateral gaze either by abnormal convergence or impaired medial rectus inhibition seems most likely.
\end{abstract}

\section{Background}

In 1921, Anton Lutz postulated the existence of a prenuclear abduction paresis, the so-called "ophthalmoplegia internuclearis posterior" (posterior internuclear ophthalmoplegia, PINO) [1]. This concept, however, was based on an erroneous neuroanatomical concept: Lutz thought that the supranuclear fibers mediating horizontal gaze divide within the pons into a descending branch to lateral rectus motoneurons on one side and an ascending branch to medial rectus motoneurons on the other 
side. The PINO was attributed to a lesion of the descending branch thought to be followed by a reduced or absent excitation of lateral rectus motoneurons. Although Lutz's basic neuroanatomical assumption was wrong, the existence of a PINO remained controversial, as a PINO was repeatedly discussed in patients, whose abduction paresis was thought to differ from a 6th nerve palsy. This included absence of strabismus and diplopia in the primary position [2-5], adduction nystagmus of the contralateral, i.e. non-paretic eye on lateral gaze $[3,4,6]$, isolated impairment of abduction saccades, i.e. unrestricted abduction with following eye movements [7], preserved abduction sacccades with caloric testing, i.e. with vestibular (caloric) nystagmus [8,9], or preserved abduction with the vestibulo-ocular reflex [9]. There was little agreement on both, the location of the responsible lesion and the underlying mechanism. Some suggested impairment of the supranuclear pathways for lateral gaze running near the 3rd nerve nucleus [9]. Others postulated a decreased excitation of lateral rectus motoneurons due to a lesion of aberrant pyramidal tract fibers to the abducens nucleus [10], or an affection of the connection between the paramedian pontine reticular formation (PPRF) and the ipsilateral abducens nucleus [5,7]. An impaired inhibition of the antagonistic medial rectus muscle was discussed by Collard et al. [4] suggesting a medial longitudinal fasciculus (MLF) lesion contralateral to the paretic eye. Finally, some authors attributed such cases to a lesion of the intrapontine segment of the 6th nerve thereby rejecting a pre- or supranuclear origin of the abduction paresis [11-14].

We re-address this issue based on findings in 33 (including 8 previously reported [15] patients with unilateral or bilateral abduction paresis with electrophysiologically or clinically documented rostral pontine and/or mesencephalic lesions.

\section{Methods}

We retrospectively identified 22 patients with isolated unilateral $(\mathrm{n}=20)$ or bilateral $(\mathrm{n}=2)$ abduction paresis, who also had electrophysiological abnormalities indicating rostral pontine and/or mesencephalic lesions. Another 11 patients with an unilateral abduction paresis as their main clinical symptom had additional clinical signs of midbrain dysfunction, which were supported by abnormal electrophysiological findings in 8 of them. None of the 33 patients had total abduction paresis. In most patients, abduction was limited to $20-30^{\circ}$ from the midposition with saccadic and following eye movements. Electrophysiologic testing in all patients included masseter and blink reflexes (MassR, BlinkR), brainstem auditory evoked potentials (BAEP), and direct current electro-oculography (EOG) as described previously $[15,16]$. Criteria of MassR and BlinkR abnormalities were: (i) unilateral or bilateral delayed latency outside the age related mean +2.5 standard deviations (SD), (ii) unilateral or bilateral loss (including partial MassR loss, i.e. loss of more than 4 responses out of 10 trials); (iii) right/left differences outside the age related mean +2.5 SD; (iv) increase or shortening of the MassR latency at re-examination by $0.8 \mathrm{~ms}$ or more was interpreted in favor of deteriorating or improving acute lesions. [15,16]. Velocities of saccades outside the normal range were considered abnormal (normal ranges of our laboratory: $30^{\circ}$-abduction saccades: 320 to $640^{\circ} / \mathrm{s} ; 30^{\circ}$-adduction saccades: 335 to $670^{\circ} / \mathrm{s}$; interocular difference $<35^{\circ} / \mathrm{s}$ ).

Magnetic resonance imaging (MRI) was done in 8 patients with 1.0 (Siemens Magnetom, Erlangen, Germany) or 1.5 Tesla (Philips S, Eindhoven, The Netherlands) superconducting systems before and after intravenous gadolinium. T1-weighted (repetition time: $500-750 \mathrm{~ms}$, echo time: $20-50 \mathrm{~ms}$ ) and T2-weighted (repetition time: 1800-2080 ms, echo time: $80-100 \mathrm{~ms}$ ) images were obtained. Slice thickness was between 4 and $7 \mathrm{~mm}$. CT was done in 19 patients with an EMI 1010 (London, United Kingdom) or Siemens Somatom ARP (Erlangen, Germany). Slice thickness was between 4 and $7 \mathrm{~mm}$.

Diagnosis of brainstem infarction was based on (a) sudden onset, (b) presence of at least one relevant risk factor for the development of cerebrovascular diseases (diabetes, hypertension, previous strokes or transient ischemic attacks, atrial fibrillation, heavy smoking, hypercholesterolemia, signs of general arteriosclerosis), and (c) subsequent improvement or recovery. Multiple sclerosis was diagnosed according to the criteria given by Poser et al. [17] and Paty et al. [18].

\section{Results}

Brainstem ischemia was diagnosed in 24 and multiple sclerosis in 4 patients. One patient had an undiagnosed inflammatory disease. In the remaining 4 patients the etiology remained undetermined.

Abnormal electrophysiologic findings are given in detail in table 1. Seventeen patients with unilateral abduction paresis, which was the only clinical signs in 12 and associated with additional clinical signs of midbrain dysfunction in 5 , had unilateral MassR abnormalities. These abnormalities were ipislateral in 16 and contralateral in one patient. One of these patients (\#9) also had a delayed BAEP wave $V$ ipsilateral to the abduction paresis and the MassR abnormality. Another 11 patients with unilateral abduction paresis, which was the only clinical signs in 8 and associated with additional clinical signs of midbrain dysfunction in 3, had bilateral MassR abnormalities, which were more pronounced on the side of the abduction paresis in 3 and without a relevant side difference in 
Table I: Abnormal electrophysiological and/or clinical findings

\begin{tabular}{|c|c|c|c|c|c|c|c|}
\hline \multirow{3}{*}{$\begin{array}{l}\text { No. } \\
\text { I }\end{array}$} & \multirow{2}{*}{$\begin{array}{l}\text { Age } \\
\text { (years) }\end{array}$} & \multirow{2}{*}{$\begin{array}{l}\text { Sex } \\
\text { female }\end{array}$} & \multirow{2}{*}{$\begin{array}{l}\text { Etiology } \\
\text { ischemia }\end{array}$} & \multirow{2}{*}{$\begin{array}{l}\text { Clinical findings } \\
\text { abduction paresis }\end{array}$} & \multicolumn{3}{|c|}{ Electrophysiological findings } \\
\hline & & & & & MassR & right & loss $\Rightarrow 8.3 \mathrm{~ms}$ \\
\hline & & & & right eye & & left & $8.0 \mathrm{~ms} \Rightarrow 7.9 \mathrm{~ms}$ \\
\hline & & & & & EOG & slowed & uction saccades left eye ${ }^{\mathrm{N}}$ \\
\hline \multirow[t]{2}{*}{2} & 76 & female & ischemia & abduction paresis & MassR & right & $9.2 \mathrm{~ms} \Rightarrow 8.8 \mathrm{~ms}$ \\
\hline & & & & right eye & & left & $8.5 \mathrm{~ms} \Rightarrow 8.7 \mathrm{~ms}$ \\
\hline \multirow[t]{2}{*}{3} & 51 & Male & undetermined & abduction paresis & MassR & right & $9.1 \mathrm{~ms} \Rightarrow 8.4 \mathrm{~ms}$ \\
\hline & & & & right eye & & left & $7.9 \mathrm{~ms} \Rightarrow 8.0 \mathrm{~ms}$ \\
\hline \multirow[t]{3}{*}{4} & 58 & female & ischemia & abduction paresis & MassR & right & $8.9 \mathrm{~ms} \Rightarrow 8.0 \mathrm{~ms}$ \\
\hline & & & & right eye & & left & $8.2 \mathrm{~ms} \Rightarrow 7.9 \mathrm{~ms}$ \\
\hline & & & & & EOG & Slowed & uction saccades left eye ${ }^{\mathrm{N}}$ \\
\hline \multirow[t]{3}{*}{5} & 33 & female & Multiple & abduction paresis & MassR & right & $6.6 \mathrm{~ms} \Rightarrow 7.1 \mathrm{~ms}$ \\
\hline & & & sclerosis & left eye & & left & $7.4 \mathrm{~ms} \Rightarrow 7.9 \mathrm{~ms}$ \\
\hline & & & & & EOG & Slowed & uction saccades right eye $\mathrm{N}^{\mathrm{N}}$ \\
\hline \multirow[t]{2}{*}{6} & 74 & Male & ischemia & abuction paresis & MassR & right & $7.3 \mathrm{~ms} \Rightarrow 7.2 \mathrm{~ms}$ \\
\hline & & & & right eye & & left & $6.6 \mathrm{~ms} \Rightarrow 7.2 \mathrm{~ms}$ \\
\hline \multirow[t]{2}{*}{7} & 68 & male & ischemia & abduction paresis & MassR & right & $9.8 \mathrm{~ms}$ \\
\hline & & & & right eye & & left & $9.1 \mathrm{~ms}$ \\
\hline \multirow[t]{3}{*}{8} & 78 & female & ischemia & abduction paresis & MassR & right & $9.6 \mathrm{~ms}$ \\
\hline & & & & right eye & & left & $8.9 \mathrm{~ms}$ \\
\hline & & & & & EOG & slowed & ades to the left $\mathrm{N}$ \\
\hline \multirow[t]{5}{*}{9} & 51 & male & ischemia & abduction paresis & MassR & right & $7.4 \mathrm{~ms}$ \\
\hline & & & & left eye & & left & $9.0 \mathrm{~ms}$ \\
\hline & & & & & BAEP & right & $5.8 \mathrm{~ms} \Rightarrow 5.9 \mathrm{~ms}$ \\
\hline & & & & & & left & $6.1 \mathrm{~ms} \Rightarrow 5.9 \mathrm{~ms}$ \\
\hline & & & & & EOG & Slowed & uction saccades right eye $\mathrm{N}^{\mathrm{N}}$ \\
\hline \multirow[t]{2}{*}{10} & 77 & male & ischemia & abduction paresis & MassR & right & $8.6 \mathrm{~ms}$ \\
\hline & & & & right eye & & left & $8.0 \mathrm{~ms}$ \\
\hline \multirow[t]{2}{*}{11} & 67 & male & ischemia & abduction paresis & MassR & right & $8.0 \mathrm{~ms}$ \\
\hline & & & & right eye & & left & $7.3 \mathrm{~ms}$ \\
\hline 12 & 39 & female & inflammation & abduction paresis & MassR & right & $6.9 \mathrm{~ms}$ \\
\hline & & & & left eye & & left & $6.1 \mathrm{~ms}$ \\
\hline & & & & & EOG & Slowed & uction saccades right eye $\mathrm{N}^{\mathrm{N}}$ \\
\hline 13 & 74 & female & ischemia & abduction paresis & MassR & right & loss $\Rightarrow$ loss \\
\hline & & & & right eye & & left & loss $\Rightarrow 7.3 \mathrm{~ms}$ \\
\hline 14 & 34 & female & Multiple & abduction paresis & MassR & right & $9.4 \mathrm{~ms}$ \\
\hline & & & sclerosis & right eye & & left & $8.5 \mathrm{~ms}$ \\
\hline & & & & & EOG & Slowed & ades to the left $\mathrm{N}^{\mathrm{N}}$ \\
\hline 15 & 26 & male & Multiple & abduction paresis & MassR & right & $8.8>4 \mathrm{~ms}$ \\
\hline & & & sclerosis & right eye & & left & $9.0 \mathrm{~ms}$ \\
\hline & & & & & EOG & Slowed & ades to the left $\mathrm{N}$ \\
\hline 16 & 68 & female & ischemia & abduction paresis & MassR & right & $9.4 \mathrm{~ms} \Rightarrow 8.0 \mathrm{~ms}$ \\
\hline & & & & left eye & & left & $9.2 \mathrm{~ms} \Rightarrow 8.0 \mathrm{~ms}$ \\
\hline 17 & 73 & male & ischemia & abduction paresis & MassR & right & $9,3 \mathrm{~ms} \Rightarrow 8.5 \mathrm{~ms}$ \\
\hline & & & & right eye & & left & $9.6 \mathrm{~ms} \Rightarrow 8.5 \mathrm{~ms}$ \\
\hline & & & & & EOG & Slowed & uction saccades left eye $\mathrm{N}^{\mathrm{N}}$ \\
\hline 18 & 68 & female & ischemia & abduction paresis & MassR & right & $9.4 \mathrm{~ms} \Rightarrow 8.0 \mathrm{~ms}$ \\
\hline & & & & left eye & & left & $9.2 \mathrm{~ms} \Rightarrow 8.0 \mathrm{~ms}$ \\
\hline 19 & 73 & male & ischemia & abduction paresis & MassR & right & $9,3 \mathrm{~ms} \Rightarrow 8.5 \mathrm{~ms}$ \\
\hline & & & & right eye & & left & $9.6 \mathrm{~ms} \Rightarrow 8.5 \mathrm{~ms}$ \\
\hline 20 & 70 & male & ischemia & abduction paresis & MassR & right & $9.1>4 \mathrm{~ms}$ \\
\hline & & & & right eye & & left & $8.9>4 \mathrm{~ms}$ \\
\hline & & & & & EOG & Slowed & ades to the left ${ }^{N}$ \\
\hline 21 & 65 & male & ischemia & abduction paresis & MassR & right & loss $\Rightarrow 8.3 \mathrm{~ms}$ \\
\hline & & & & left > right eye & & left & $8.6 \mathrm{~ms} \Rightarrow 8.6 \mathrm{~ms}$ \\
\hline 22 & 55 & male & undetermined & abduction paresis & MassR & right & $11.8 \mathrm{~ms} \Rightarrow 10.3 \mathrm{~ms}$ \\
\hline & & & & right > left eye & & left & $9.4 \mathrm{~ms} \Rightarrow 9.0 \mathrm{~ms}$ \\
\hline 23 & 48 & male & ischemia & abduction paresis plus & MassR & right & $7.9 \mathrm{~ms} \Rightarrow 8.1 \mathrm{~ms}$ \\
\hline
\end{tabular}


Table I: Abnormal electrophysiological and/or clinical findings (Continued)

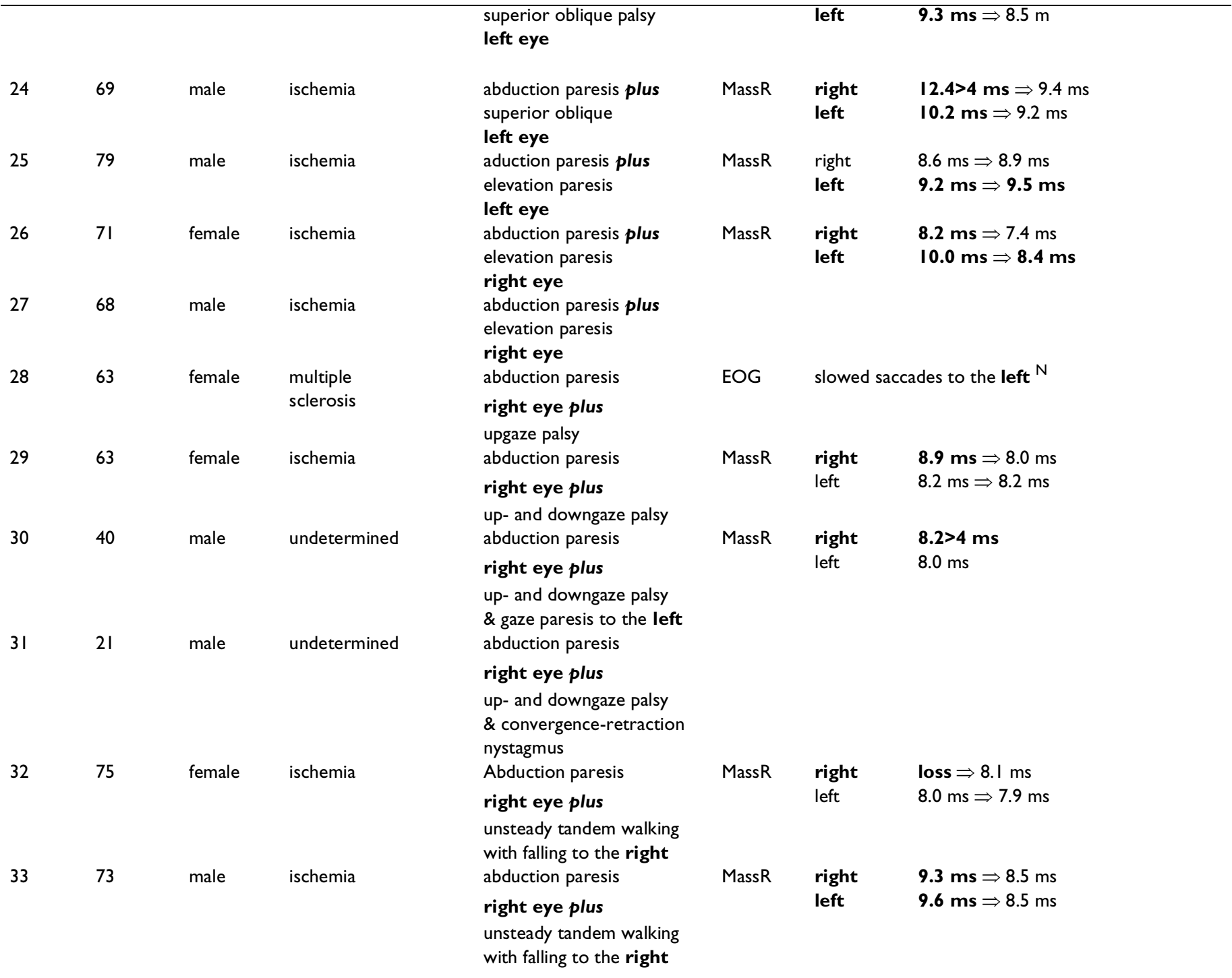

the remaining patients. Both patients with bilateral abduction paresis (\#21 and \#22) had unilateral MassR abnormalities. BlinkR was normal in all patients.

EOG disclosed slowed abduction saccades in the opposite eye in 6 patients with velocities ranging between 379 and $523^{\circ} / \mathrm{s}$, which was by 123 to $199^{\circ} / \mathrm{s}$ slower than adduction saccades in the non-paretic eye. Another 5 patients had slowed saccades to the side opposite to the abduction paresis with velocities for $30^{\circ}$-saccades ranging between 323 and $478^{\circ} / \mathrm{s}$, which was by 109 to $228^{\circ} / \mathrm{s}$ slower than adduction saccades in the non-paretic eye.
Re-examinations were done in 27 patients documenting normalized or improved MassR abnormalities in 18 and unchanged abnormal MassR findings in 2 patients. The delayed BAEP wave $V$ latency (patient \#9) was normal at re-examination. EOG documented saccadic slowing had improved or normalized in all patients.

MRI (8 patients) and CT (19 patients) revealed no brainstem lesions except MRI documented bilateral symmetrical pontine hyperintensities without signs of acute infarctions in one patient with vertebrobasilar ischemia. (MRI disclosed multiple periventricular hyperintense lesions in two patients with multiple sclerosis and multiple 
supratentorial white matter lesions in 6 patients with risk factors for cerevbrovascular disease.

\section{Discussion}

Thirty of our patients had electrophysiologically documented rostral pontine and/or mesencephalic lesions. Unilateral MassR abnormalities were almost always on the side of the abduction paresis, which argues against a random association. Pre-existing electrophysiological abnormalities were unlikely, as almost all (19 of 21) reexamined patients showed improvement or normalization of abnormal MassR and BAEP findings, which strongly suggests acute lesions. This was always associated with improvement of the abduction paresis, which strongly indicates that both, clinical and electrophysiological abnormalities, were caused by the same actual lesion. Abnormal MassR findings in patients with normal trigeminal nerve sensory and motor function indicate lesions involving the ipsilateral trigeminal mesencephalic tract and nucleus [see for review [19,20]]. This corresponds to the rostral pons and mesencephalon between the level of the $5^{\text {th }}$ nerve entry zone and the 3 rd nerve nucleus level. An abnormal R1-component of the BlinkR (Blink-R1) with normal R2 components and normal trigeminal and facial nerve functions indicates an ipsilateral pontine lesion between the trigeminal nerve entry zone and the facial nucleus [see for review $[19,20]]$. Abnormal MassR findings with normal BlinkR-R1 as seen in 30 of our patients indicate rostral pontine and/or mesencphalic lesions [19,20]. Midbrain dysfunction was also evident from vertical gaze palsies and convergence nystagmus [21], which were seen in 4 of our patients. Such lesion location is clearly rostral to the intrapontine segment of the 6th nerve excluding an infranuclear intrapontine 6th nerve lesion in our patients.

Our patients correspond to a number of previously reported patients, most of them with pathologically or radiologically proven midbrain or meso-diencephalic lesions, showing an abduction paresis with additional clinical signs of midbrain dysfunction like upgaze palsy, convergence paresis, or convergence nystagmus [3,7,9,22-29]. Such location was also obvious in another 2 patients with transient abduction paresis after ipsilateral mesencephalotomy [30]. These observations and our data leave no doubt on the existence of an abduction paresis with ipsilateral rostral pontine and/or mesencephalic lesions, even though we were unable to demonstrate CT or MRI documented brainstem lesions. Small brainstem lesions definitely escape observation by CT and "routine" MRI (=T1- and T2-weighted imaging with thick (4-7 mm) slices) as shown with pathologically documented brain stem infarctions [31,32], internuclear ophthalmoplegia [33-35], monocular elevation paresis [36], isolated 3rd, 4th, 6th, 7th, and 8th nerves palsies in multiple sclerosis [37-41], and electrophysiologically documented brainstem lesions [15,36,39,42-49]. Thinner slicing and other recent techniques (e.g. diffusion weighted imaging, perfusion imaging, fluid attenuated inversion recovery) have increased MRI sensitivity [5054]. Such techniques, however, were not applied to our patients. Moreover, lesions impairing the function of certain brainstem structures not necessarily impair the structural integrity and therefore may escape detection by MRI even with thinner slicing and diffusion weighted imaging [54,55]. Functional abnormalities, both clinical and electrophysiological, can be estimated equal reliable in indicating the location of a brainstem lesion if they have been correlated with imaging or pathologically documented lesion locations, which has been worked out for brainstem reflexes and clinical signs [see for review [1921].

Supranuclear excitatory connections mediating horizontal gaze simultaneously activate lateral rectus motoneurons and, via abducens nucleus internuclear neurons, medial rectus motoneurons $[56,57]$. Lesions of these fibres within the midbrain are followed by horizontal gaze disorders simultaneously affecting abduction in one and adduction in the other eye $[56,57]$. Abduction paresis in one without impaired adduction in the other eye as in our patients can not be attributed to a lesion of descending excitatory fibres mediating horizontal gaze, which excludes supranuclear impairment of lateral rectus activation as the working mechanism in our patients. Abduction paresis in our patients were most likely caused by abnormal convergence or impaired medial rectus inhibition during lateral gaze. Both conditions create an increased tone of the antagonistic medial rectus muscle causing abduction paresis despite normal lateral rectus activation.

Abduction paresis with organic and non-organic convergence spasm documents the functional significance of an abnormal convergence during lateral gaze [58-61]. Abduction paresis may also occur (not infrequently in association with convergence or convergence-retraction nystagmus as in patient \#31) as one sign of the dorsal midbrain syndrome and is generally attributed to an abnormal convergence tone during lateral gaze $[62,63]$. Such mechainsm was discussed as the most likely cause in patients with unilateral or bilateral abduction paresis with or without esotropia of the affected eye occurring with meso-diencephalic infarctions [24,26-29] and called "pseudo-sixth" [24] or "pseudoabducens palsy" [29]. Convergence neurons are located within the mesencephalic reticular formation. Their discharge is timecoupled to convergence eye movements and encodes their velocity [see for review [64]]. The supranuclear control of these neurons is not fully understood, but may 
involve several connections. In primates, there is evidence for an excitatory projection from area 19 and 22 to the midbrain. Stimulation in these areas was followed by ipsilateral or ipsilaterally pronounced convergence movements with or without miosis depending on the intensity and exact location of the stimulation $[65,66]$. Another bilateral, mainly ipsilateral, projection from the frontal lobe to the midbrain was also shown in primates $[67,68]$ and considered to exert direct inhibition of a subgroup of rectus medialis motorneurons (27), the group C of Büttner-Ennever und Akert, which is thought to be primarily involved in convergence eye movements [69]. A lesion of this connection within the midbrain would be followed by a disinhibition of convergence neurons creating an increased convergence tone during lateral gaze because of the preponderance of the excitatory projection from area 19 and 22 [27]. More recently, Pullicino et al. [29] provided convincing evidence, that the region of the interstitial nucleus of Cajal, which has a close proximity to convergence neurons in the monkey [70], may be critical for the occurrence of a "pseudoabducens palsy" due to a lesion of a descending pathway just before it reaches the convergence neurons.

Lesions involving rostral parts of the central MassR arc may extend beyond this level reaching the meso-diencephalic junction thereby involving the region of the interstitial nucleus of Cajal. Such localized lesions were likely in a number of our patients because of additional clinical signs such as vertical gaze palsies (patients \#2931 ), monocular elevation paresis (patients \#25-27), and convergence retraction nystagmus (patient \#31), which was associated with ipsilateral MassR abnormalities in 4 of them. All previously described patients with an abduction paresis due to upper brainstem infarcts had additional clinical signs of rostral midbrain dysfunction (e.g. vertical gaze palsies, convergence retraction nystagmus) [24,26-29]. Such signs, however, were not seen in most of our patients indicating either more restricted rostral midbrain lesions involving descending fibres to convergence neurons with sparing of adjacent structures, or more caudally located, rostral pontine and/or pontomesencephalic lesions. Such lesion location is caudal to the level of the convergence neurons, which excludes damage of descending fibres involved in the control of convergence thereby also excluding abnormal convergence as the underlying mechanism of the abduction paresis in these patients.

Inhibition of antagonistic eye muscles may cause paresis of vertical and horizontal eye movements despite normal excitation of agonistic eye muscles [23,71-73]. Impaired medial rectus inhibition may occur with midbrain lesions as documented in a patient with an unilateral convergence paresis as a clinical sign of an ipsilateral midbrain dysfunction, who also had an ipsilateral abduction paresis with grossly impaired medial rectus inhibition and normal lateral rectus excitation [23]. Medial rectus inhibition was attributed to several different mechanisms. Pola and Robinson [74] proposed the existence of inhibitory fibres ascending within the medial longitudinal fasciculus (MLF). As MLF fibre activity is always associated with contraversive eye movements, i.e. ipsilateral to the adducting eye [74,75], inhibitory MLF fibers would have to cross at the 3 rd nerve nucleus level to reach the medial rectus motoneurons on the side of the abducting eye [74]. Such crossing of MLF fibres, however, has not been demonstrated so far $[76,77]$.

Pierrot-Deseilligny [78] discussed an inhibition of excitatory abducens nucleus internuclear neurons ("disfacilitation") as the working mechanism of medial rectus inhibition. This inhibition was attributed to the activity of inhibitory burst neurons located within the dorsomedial pontine reticular formation, which receive afferents from the ipsilateral PPRF and project to contralateral abducens nucleus neurons [79,80]. Bilateral interruption of this connection and of both MLF, however, was followed by bilateral INO and bilateral loss of lateral rectus inhibition but only mild impairment of medial rectus inhibition [71]. Moreover, loss of excitatory MLF fibre activity is not associated with a reduced tonic resting activity of the medial rectus muscle [81-83]. These findings do not support the concept that inhibition of excitatory abducens nucleus internuclear neurons is important for medial rectus inhibition.

There is some experimental data supporting the concept of an inhibitory projection to medial rectus motoneurons: Fibre degeneration studies in rabbits [84] and primates [85] and autoradiographic studies in cats [86] and primates $[76,87]$ demonstrated an uncrossed connection between the pontine reticular formation and the 3 rd nerve nucleus. This projection originates from neurons in the pontine reticular formation between the level of the 4th and 6th cranial nerve nuclei [88] ascending adjacent but separate from the MLF $[76,85]$, and approaching medial rectus motoneurons [87]. Stimulation of these neurons in animals with bilaterally destructed MLFs was followed by monosynaptic inhibitory potentials in ipsilateral 3 rd nerve nucleus neurons and ipsilateral medial rectus motoneurons [88-90]. If this connection mediates medial rectus inhibition, its lesion would be followed by an abduction paresis with normal lateral rectus activation but impaired medial rectus inhibition.

The locations of the responsible lesions thought to be followed by an impaired medial rectus inhibition or abnormal convergence during lateral gaze are in accordance to 
both, abnormal electrophysiological and clinical findings, and to an ischemic origin of the lesions as diagnosed in most of our patients. The regions in question, i.e. the midbrain area containing convergence neurons, the region of the uncrossed inhibitory connection, and the trigeminal mesencephalic tract and nucleus forms a watershed zone. It is supplied by long penetrating branches of the basilar artery with additional contributions from paramedian, lateral, and dorsolateral branches of the posterior cerebral artery and the superior cerebellar artery $[91,92]$. Occlusion of a long penetrating artery may cause unilateral or bilateral lesions, as these arteries often show an asymmetric termination [91,92], which explains bilateral MassR abnormalities in our patients. EOG documented slowed abduction saccades on non-paretic may also be attributed to asymmetric bilateral lesions. The close relation of the mesencephalic tract and nucleus of the trigeminal nerve to both, mesencephalic convergence neurons and the probably inhibitory connection between the pontine reticular formation and the medial rectus subnucleus, explains abnormal MassR findings in our patients. Slowed contraversive saccades (in 5 of our patients) may also occur with lesions near the 3rd nerve nucleus, if such lesions involve the descending excitatory fibres to the paramedian pontine reticular formation before its crossing at the $3 \mathrm{rd} / 4$ th nerve nucleus level. A combined abduction and superior oblique palsy in the same eye and an ipsilateral MassR abnormality, which is caused by a single responsible lesions, can only be attributed to a midbrain lesion involving the intra-axial segment of the crossed 4th nerve, which runs closely related to the probably inhibitory connection and the trigeminal mesencephalic tract and nucleus. Monocular elevation paresis and abduction paresis in the same eye may also be caused by a single ipsilateral midbrain lesion involving the probably inhibitory connection and the intramesencephalic 3rd nerve, as monocular elevation paresis may also be caused by intraaxial 3rd nerve lesions [93].

\section{Conclusions}

Our data add further evidence on the existence of an abduction paresis with rostral pontine or mesencephalic lesions. With such locations, the most likely explanation is an increased tone of the antagonistic medial rectus muscle during lateral gaze, which may be due to abnormal convergence or impaired medial rectus inhibition. Both mechanisms are followed by "a failure of ocular abduction which is not due to dysfunction of the sixth nerve" [24]. Such ocular motor disorder resembles the ominous and unsettled "posterior internuclear ophthalmoplegia" of Lutz only with respect to its prenuclear origin, but not its mechanism. An impaired excitation of the lateral rectus muscle in one eye without impaired excitation of the medial rectus muscle in the other eye, as proposed by
Anton Lutz, is not compatible with the proven prenuclear organisation of horizontal eye movements. All kinds of horizontal eye movements (saccades, pursuit, vestibulo-ocular-reflex) are generated by an excitation of both, abducens nucleus motoneurons and internuclear neurons [see for review [57]]. This is followed by the simultaneous activation of the lateral rectus muscle in one eye (via projections of lateral rectus motoneurons) and the medial rectus muscle in the other eye (via the projections of abducens nucleus internuclear neurons, which cross at the abducens nucleus level and ascend in the medial longitudinal fasciculus to medial rectus motoneurons). Impaired excitation of the lateral rectus muscle without excitation of the medial rectus muscle in the opposite eye can not occur with lesions of prenuclear excitatory connections mediating horizontal gaze. This is only seen with infranuclear lesions of the 6th nerve. An increased tone of the antagonistic medial rectus muscle during lateral gaze is the only possible mechanism of an abduction paresis, which is not caused by a sixth nerve lesion. Such an ocular motor disorder should be called "pseudoabducens palsy" [29] or "pseudo-sixth" [24], because the term "posterior INO" was introduced on the basis of an erroneous neuroanatomical concept. Moreover, Cogan [94] had his own anterior and posterior types of internuclear ophthalmoplegia (INO) using the term "posterior INO" for the well known INO (= adduction paresis on lateral gaze and preserved adduction during convergence), and the term "anterior INO" for an INO with convergence paresis, which further confuses terminology [95].

Diagnosis of a pseudoabducens palsy should only be considered in patients with clinical, electrophysiological, or morphological evidence of an ipsilateral rostral pontine or mesencephalic lesion. In our experience, such an eye movement disorder is very rare with an incidence of less than one tenth as compared to the incidence of the well known internuclear ophthalmoplegia with adduction paresis on lateral gaze but usually preserved adduction during convergence.

\section{Competing interests}

\section{None declared}

\section{References}

I. Lutz A: Über die Bahnen der Blickwendung und deren Dissoziierung. (Nebst eines Falles von Ophthalmoplegia internuclearis anterior in verbindung mit Dissoziierung der Bogengänge). Klin Monatsbl Augenheilkd 1923, 70:213-235

2. Larmande A-M: La paralysie supranucléaire du VI.(dite ophthalmoplégie internucléaire postérieure). Arch $d^{\prime}$ Ophtalmol (Paris) 1969, 29:521-530

3. Schiffter R: Die internukleären Ophthalmoplegien. Klinische Analyse von 25 Kranheitsfällen. Nervenarzt 1975, 46:। I6-I27

4. Collard M, Eber AM, Streicher D, Rohmer F: L'ophthalmoplégie internucléaire postérieure-existe-t-elle? A propos de onze observations avec oculographie. Rev Neurol 1979, I 35:293-3 I2 
5. Topilow HW: Posterior internuclear ophthalmoplegia of Lutz. Ann Ophthalmol I98I, I3:22I-226

6. Bogousslavsky J, Regli F, Ostinelli B, Rabinowicz T: Paresis of lateral gaze alternating with so-called posterior internuclear ophthalmoplegia. A partial pontine reticular formation-abducens nucleus syndrome. J Neurol 1985, 232:38-42

7. Kommerell G: Internuclear ophthalmoplegia of abduction. Isolated impairment of phasic ocular motor activity in supranuclear lesions. Arch Ophthalmol 1975, 93:531-534

8. Walsh FB, Hoyt WF: Clinical Neuro-Ophthalmology, Baltimore, Williams \& Wilkins 1969, Vol. I:239-243

9. Yokota Jl, Imai H, Mizuno Y, Hishii M, Ito M: Unilateral supranuclear abducens palsy in a pineal tumor. No-To-Shinkei 1994, 46:29I-295

10. Rothstein TL, Alvord EC: Posterior internuclear ophthalmoplegia. A clinicopathological study. Arch Neurol I97I, 24:191-202

II. Fine M, Mac Glashan CB: Unilateral internuclear ophthalmoplegia of vascular origin. Arch Ophthalmol 1956, 56:327-337

12. Henn V, Büttner U, Büttner-Ennever JA: Supranukleäre Organisation der Okulomotorik-physiologische und anatomische Grundlagen. In: Augenbewegungsstörungen. Neurophysiologie und Klinik (Edited by Kommerell G) München, Bergmann 197829-|4I

13. Oliveri RL, Bono F, Quattrone A: Pontine lesion of the abducens fasciculus producing so-called posterior internuclear ophthalmoplegia. Eur Neurol 1997, 37:67-69

14. Wiest G, Wanschitz J, Baumgärtner C, Trattnig S, Deecke L, Mueller C: So-called posterior internuclear ophthalmoplegia due to a pontine glioma: a clinicopathological study. I Neurol 1999, 246:4I2-4|5

15. Thömke F, Hopf HC, Krämer G: Internuclear opththalmoplegia of abduction. Clinical and electrophysiological data on the existence of an abduction paresis of prenuclear origin. J Neurol Neurosurg Psychiatry 1992, 55:105-1II

16. Thömke F, Hopf HC: Pontine lesions mimicking acute peripheral vestibulopathy. J Neurol Neurosurg Psychiatry 1999, 66:340-349

17. Poser CM, Paty DW, Scheinberg L, McDonald WI, Davis FA, Ebers GC, Johnson KP, Sibley WA, Silberberg DH, Tourtelotte WW: New diagnostic criteria for multiple sclerosis: Guidelines for research protocols. Ann Neurol I983, 13:227-231

18. Paty DW, Asbury AK, Herndon RM, McFarland HF, McDonald WI, Mcllroy WJ, Prineas JW, Scheinberg LC, Wolinsky JS: Use of magnetic resonance imaging in the diagnosis of multiple sclerosis: Policy statement. Neurolgy 1986, 36:1575

19. Hopf HC: Topodiagnostic value of brain stem reflexes. Muscle Nerve 1994, 17:475-484

20. Thömke F: Isolated cranial nerve palsies due to brainstem lesions. Muscle Nerve 1999, 22:1 168-1176

21. Leigh RJ, Zee DS: Ocular motor syndromes caused by lesions of the mesencephalon. In: The Neurology of Eye Movements (by Leigh RJ, Zee DS) New York, Oxford University Press 19995। I-526

22. Körney S: Blickstörungen bei vasculären Herden des mesodiencephalen Übergangsgebietes. Arch Psychiat $Z$ ges Neurol I959, 1 98:535-543

23. Orlowski WJ, Slomski P, Wojtowicz S: Bielschowsky-Lutz-Cogan syndrome. Am J Ophthalmol 1965, 59:416-430

24. Caplan LR: "Top of the basilar" syndrome. Neurology 1980, 30:72-79

25. Weisberg LA: Mesencephalic hemorrhages: clinical and computed tomographic correlations. Neurology 1986, 36:713-7I6

26. Rousseaux M, Petit H, Hache JC, Devos P, Dubois F, Warot P: La motricite oculaire et cephalique dans les infarctus de la region thalamique. Rev Neurol 1985, 14 1:391-403

27. Gomez CR, Gomez SM, Selhorst JB: Acute thalamic esotropia. Neurology 1988, 38:1759-1762

28. Namer IJ, Öztekin MF, Kansu T, Zilli T: Pseudo-sixth nerve palsy with thalamo-mesencephalic junction lesion. Report of two cases. Neuro-ophthalmology 1990, 10:69-72

29. Pullicino $P$, Lincoff N, Truax BT: Abnormal vergence with upper brainstem infarcts. Pseudoabducens palsy. Neurology 2000, 55:352-358

30. Nashold BS, Gills JP: Ocular signs from brain stimulation and lesions. Arch Opthalmol 1967, 77:609-618

31. Alberts MJ, Faulstich ME, Gray L: Stroke with negative brain magnetic resonance imaging. Stroke 1992, 23:663-667
32. Besson G, Hommel M, Clavier I, Perret J: Failure of magnetic resonance imaging in the detection of pontine lacune. Stroke 1992, 23:1535-1536

33. Rumbach L, Eber AM, Dietemann JL, Bataillard M, Tranchant C, Warter JM, Collard M: Apport de I'I.R.M. au diagnostic topographique des troubles oculomoteurs dans la sclérose en plaques. Rev Neurol 1990, I46:30-35

34. Bronstein AM, Rudge P, Gresty MA, du Boulay G, Morris J: Abnormalities of horizontal gaze. Clinical, oculographic and magnetic resonance imaging findings. II. Gaze palsy and internuclear ophthalmoplegia.J Neurol Neurosurg Psychiatry 1990, 53:200-207

35. Mutschler V, Eber AM, Rumbach L, Dietemann JL, Bataillard M, Collard M: Internuclear ophthalmoplegia in 14 patients. Clinical and topographic correlation using magnetic resonance imaging. Neuro-ophthalmology 1990, 10:319-235

36. Thömke F, Hopf HC: Aquired monocular elevation paresis - An asymmetric upgaze palsy. Brain 1992, II5:1901-1910

37. Newmann NJ, Lessell S: Isolated pupil-sparing third-nerve palsy as the presenting sign of multiple sclerosis. Arch Neurol 1990, 47:817-818

38. Rose JW, Digre KB, Lynch SG, Harnsberger RH: Acute VIth cranial nerve dysfunction in multiple sclerosis. I Clin Neuro-ophthalmol 1993, I 2:17-20

39. Thömke F, Lensch E, Ringel K, Hopf HC: Isolated cranial nerve palsies in multiple sclerosis. J Neurol Neurosurg Psychiatry 1997, 63:682-685

40. Jacobson DM, Moster ML, Eggenberger ER, Galetta SL, Liu GT: Isolated trochlear nerve palsy in patients with multiple sclerosis. Neurology 1999, 53:877-879

41. Fukazawa T, Moriwaka F, Hamada T, Tashiro K: Facial palsy in multiple sclerosis. J Neurol 1997, 244:63 I-633

42. Comi G, Martinelli V, Medaglini S, Locatelli T, Filippi M, Canal N, Triulzi F, DelMaschio A: Correlation between multimodal evoked potentials and magnetic resonance imaging in multiple sclerosis. J Neurol 1989, 236:4-8

43. Hopf HC, Gutmann L: Diabetic 3rd nerve palsy: evidence for a mesencephalic lesion. Neurology 1990, 40:104I-1045

44. Uncini A, Faricelli A, Assetta M, Serio A, Tartaro A, Gambi D: Electrophysiological and magnetic resonance imaging correlates of brainstem demyelinating lesions. Electromyogr clin Neurophysiol 1990, 30:233-238

45. Tettenborn B: Multifocal ischemic brain-stem lesions. In: Brainstem localization and function (Edited by Caplan LR, Hopf HC) Berlin Springer | 99323-31

46. Thömke F, Tettenborn B, Hopf HC: Third nerve palsy as the sole manifestation of midbrain ischemia. Neuro-ophthalmology 1995 , 15:327-335

47. Thömke F: Isolated abducens palsies due to pontine lesions. Neuro-ophthalmology 1998, 20:91-100

48. Thömke F, Hopf HC: Pontine lesions mimicking acute peripheral vestibulopathy. J Neurol Neurosurg Psychiatry 1998, 66:340-349

49. Thömke F, Hopf HC: Isolated superior oblique palsies with electrophysiologically documented brainstem lesions. Muscle Nerve 2000, 23:267-270

50. Hanstock CC, Faden AI, Bendall MR, Vink R: Diffusion-weighted imaging differentiates ischemic tissue from traumatized tissue. Stroke 1994, 25:843-848

51. Fisher M, Prichard JW, Warach S: New magnetic resonance technique for acute ischemic stroke JAMA I995, 274:908-9II

52. Rydberg IN, Riederer S], Rydberg CH, Jack CR: Contrast optimization of fluid-attenuated inversion recovery (FLAIR) imaging. Magn Reson Med 1995, 34:868-877

53. Ashikaga R, Araki $Y$, Ishida O: MRI of head injury using FLAIR. Neuroradiology 1997, 39:239-242

54. Mika-Grüttner A, Thömke F, Marx J], Urban PP, Ringel K, Hopf HC: MRI versus electrophysiologic testing in internuclear ophthalmoplegia. 2nd European Meeting on Brainstem Reflexes, Functions and Related Movement Disorders. Amsterdam. Movement Disorders [Abstract], 200I

55. Marx JJ, Thömke F, Fitzek S, Vucurevic G, Fitzek C, Mika-Grüttner A, Urban PP, Stoeter P, Hopf HC: Topodiagnostic value of blink reflex RI changes - A digital postprocessing MRI correlation study. Muscle \& Nerve,

56. Bender MB, Shanzer S: Oculomotor pathways definded by electrical stimulation and lesions in the brainstem of monkey. In: 
The Oculomotor System (Edited by Bender MB) New York, Harper and Row $196481-140$

57. Leigh RJ, Zee DS: Brain stem connections for horizontal conjugate movements. In: The Neurology of Eye Movements (by Leigh RJ, Zee DS) New York, Oxford University Press 1999215-221

58. Griffin JF, Wray SH, Anderson DP: Misdiagnosis of spasm of the near reflex. Neurology 1976, 26:1018-1020

59. Guiloff RJ, Whiteley A, Kelley RE: Organic convergence spasm. Acta neurol scand 1980, 6 I:252-259

60. Dagi LR, Chrousos GA, Cogn DC: Spasm of the near reflex associated with organic disease. Am J Ophthalmol 1987, I 03:582-585

61. Moster ML, Hoenig EM: Spasm of the near reflex associated with metabolic encephalopathy. Neurology 1989, 38:150

62. Ochs AL, Stark L, Hoyt WF, D'Amico D: Opposed adducting saccades in convergence-retraction nystagmus. A patient with sylvian aqueduct syndrome. Brain 1979, 102:497-508

63. Keane JR: The pretectal syndrome. 206 patients. Neurology 1990, 40:684-690

64. Leigh RJ, Zee DS: Vergence eye movements. In: The Neurology of Eye Movements (by Leigh RJ, Zee DS) New York, Oxford University Press 1999286-318

65. Jampel RS: Representation of the near response on the cerebral cortex of the macaque. Am J Ophthalmol 1959, 48:573-582

66. Jampel RS: Convergence, divergence, pupillary reactions and accomodation of the eyes from faradic stimulation of the macaque brain. I Comp Neurol 1960, I I 5:371-397

67. Leichnetz GR: The prefrontal cortico-oculomotor trajectories in the monkey. A possible explanation for the effects of stimulation/lesion experiments on eye movements. J Neurol Sc I 98I, 49:387-396

68. Leichnetz GR, Spencer RF, Hardy SGP, Astruc J: The prefrontal corticotectal projection in the monkey. An anterograde and retrograde horseradish peroxidase study. Neuroscience 1981, 6: $1023-104 \mid$

69. Büttner-Ennever JA, Akert K: Medial rectus subgroups of the oculomotor nucleus and their abducens nucleus internuclear input. J. Comp Neurol 1981, 197:17-27

70. Mays LE: Neural control of vergence eye movements: convergence and divergence neurons in midbrain. J Neurophysiol I 984, 5 I:1091-II08

7I. Burde RM, Lehman RAW, Roper-Hall G, Brooks J, Keltner JL: Experimental internuclear ophthalmoplegia. Brit. J. Ophthalmol 1977 , 6I:233-239

72. Pinhas I, Pinhas A, Goldhammer V, Braham J: Progressive supranuclear palsy: Electromyographic examinations of eye muscles. Acta neurol scandinav 1978, 58:304-308

73. Agnetti V, Traccis S, Depperu PV, Azzera GB: Internuclear ophthalmoplegia of abduction: Ocular EMG patterns. In: Neurogenetics and Neuro-ophthalmology (Edited by Huber A, Klein D) Amsterdam, Elsevier 1981263-266

74. Pola J, Robinson DA: An explanation of eye movements seen in internuclear ophthalmoplegia. Arch Neurol 1976, 33:447-452

75. King WM, Lisberger SG, Fuchs AF: Responses of fibers in the medial longitudinal fasciculus (MLF) of alert monkeys during horizontal and vertical conjugate eye movements evoked by vestibular or visual stimuli. I Neurophysiol | 976, 39: I |35- | | 49

76. Büttner-Ennever JA, Henn V: An autoradiographic study of the pathways from the pontine reticular formation involved in horizontal eye movements. Brain Res 1976, 108:155-164

77. Steiger HJ, Büttner-Ennever JA: Oculomotor nucleus afferents in the monkey demonstrated with horseradish peroxidase. Brain Res 1979, 160:1-15

78. Pierrot-Deseiligny C: Circuits oculomoteurs centraux. Rev Neurol 1985, 141:349-370

79. Highstein SM, Maekawa K, Steinacker A, Cohen B: Synaptic input from the pontine reticular nuclei to abducens motoneurons and internuclear neurons in the cat. Brain Res 1976, I I 2:162-167

80. Scudder CA, Fuchs AF, Langer TP: Characteristics and functional identification of saccadic inhibitory burst neurons in the alert monkey. J Neurophysiol 1988, 59:|430-1454

81. Loeffler JD, Hoyt WF, Slatt B: Motor excitation and inhibition in internuclear palsy. Arch Neurol 1966, I5:664-67

82. Gonzalez C, Reuben RN: Ocular electromyography in the syndrome of the median longitudinal fasciculus. Patterns of inhibition and excitation. Am J Ophthalmol 1967, 64:916-926
83. Pierrot-Deseilligny $\mathrm{C}$, Rigolet $\mathrm{MH}$, Chain F: Etude électromyographique de deux cas d'ophtalmoplégie internucléaire: Déductions physiopathologiques. Rev Neurol 1979, I 35: | 43-I52

84. Matano S: Experimental Studies on the medial longitudinal fasciculus in the rabbit. $V$. Ascending fibers from the reticular formation and the oculomotor system. J Hirnforsch 1970, | 2:24|-253

85. Goebel HH, Komatsuzaki A, Bender MB, Cohen B: Lesions of the pontine tegmentum and conjugate gaze paralysis. Arch Neurol | 97|, 24:43|-440

86. Graybiel AM: Direct and indirect preoculomotor pathways of the brainstem: An autoradiographic study of the pontine reticular formation in the cat. J Comp Neurol 1977, I 75:37-78

87. Büttner-Ennever JA, Miles TA, Henn V: The role of the pontine reticular formation in oculomotor function. Exp Brain Res 1975 23(Suppl):3 I

88. Remmel RS, Skinner RD, Pola J: Cat pontomedullary reticular neurons projecting to the regions of the ascending MLF and the vestibular nuclei. Control of gaze by brain stem neurons (Edited by Baker A, Berthoz A) Amsterdam, Elsevier 1977163-166

89. Highstein SM, Cohen B, Matsunami K: Monosynaptic projections from the pontine reticular formation to the IIIrd nucleus in the cat. Brain Res 1975, 75:340-344

90. Grantyn A, Grantyn R, Gaunitz U, Robin KP: Sources of direct excitatory and inhibitory inputs from the medial rhombencephalic tegmentum to lateral and medial rectus motoneurons in the cat. Exp Brain Res 1980, 39:49-6I

91. Hassler O: Arterial pattern of human brainstem. Normal appearance and deformation in expanding supratentorial conditions. Neurology 1967, I 7:368-375

92. Duvernoy AM: Human brainstem vessels. Berlin, Springer 1978

93. Gauntt CD, Kashii S, Nagata I: Monocular elevation paresis caused by an oculomotor fascicular impairment. J Clin NeuroOphthalmol 1995, I5:1।-14

94. Cogan DG: Neurology of the ocular muscles. Springfield, Charles C. Thomas 1956

95. Zee DS: Supranuclear and internuclear ocular motor disorders. In: Walsh \& Hoyt's Clinical Neuro-Ophthalmology, Vol. I (Edited Miller NR, Newman NJ). Baltimore; Williams \& Wilkins I998I 283-I 349

Publish with BioMed Central and every scientist can read your work free of charge

"BioMedcentral will be the most significant development for disseminating the results of biomedical research in our lifetime." Paul Nurse, Director-General, Imperial Cancer Research Fund

Publish with BMC and your research papers will be:

- available free of charge to the entire biomedical community

- peer reviewed and published immediately upon acceptance

- cited in PubMed and archived on PubMed Central

- yours - you keep the copyright 